\title{
Calculation Method of Lithium Power Battery Internal Resistance Based on Freedom Model
}

\author{
Haiying Wang ${ }^{1, *}$, Yanqiu $\mathrm{He}^{1}$, Tianjun $\mathrm{Sun}^{1}$ and Gechen $\mathrm{Li}^{1,2}$ \\ ${ }^{1}$ School of Automation, Harbin University of Science and Technology, Harbin, China \\ ${ }^{2}$ CENS Energy-TechCo.Ltd, Hangzhou, China \\ wanghy@hrbust.edu.cn
}

\begin{abstract}
Lithium power battery as the power source of the electric vehicle in series and parallel way, due to the performances of each monomer battery are inconsistent, it will seriously influence on the performance of the battery charges and discharges, and the incomplete consistency of the battery internal resistance is one of the reasons that affect these differences. In order to obtain the internal resistance of electric vehicle lithium power battery accurately, this article uses the FreedomCAR equivalent circuit model, adopting multiple linear regression algorithm which based on LINEST function. And the model and algorithm are verified and tested, the experimental results show that if adjusting the polarization time parameter constantly, we may reduce the estimation error, and we can calculate the internal resistance of the battery accurately.
\end{abstract}

Keywords: lithium ion power battery; FreedomCAR; equivalent circuit model; multiple linear regressions

\section{Introduction}

As a power source for electric vehicles, lithium batteries are usually grouped in series or parallel applications. Because of manufacturing variations in the individual cells and the difference in the charge-discharge cycles, it causes that the internal resistance of the cells are not completely identical. The electric car battery in the process of charging and discharging, the inconsistency between the battery monomer will seriously affect the performance of the battery. The precise measurement of the size of battery internal resistance is very complex, and in the process of the battery will be constantly changing, so the accurate estimation of battery internal resistance model is used for calculating internal resistance.

Commonly used in the research and development of battery power battery model is battery performance model, battery external characteristics are described by the mathematical relationship, with a variety of structures, relatively easy to use. The performance of the battery model is also known as external characteristic model. In the battery external characteristic model, the equivalent circuit model, empirical model and neural network model are often used. Equivalent circuit model has Rint model [1], RC network model and the U.S. PNGV model [2] (modified for the Freedom model [3]) and nonlinear(GNL) equivalent circuit models [4] proposed by Tsinghua university, etc; A typical neural network model is a BP network model [5]; empirical models have Unnewehr model and Shepherd model [6], etc. Currently, the most widely used in the external characteristics models of battery is the equivalent circuit model. 
In this paper, a lithium battery consistency evaluation method is proposed which is based on the model of the battery internal resistance. It uses the FreedomCAR equivalent circuit model and multiple linear regression algorithm based on the LINEST function [7]. And the model and algorithm are verified and tested, the experimental results show that the model can get more accurate battery inner resistance.

\section{The Influence of the Internal Resistance on Battery Group}

In practical applications, the connection modes of monomer battery include: seriesconnected after parallel-connected and parallel-connected after series-connected [8]. The connection modes are shown in Figure 2-1 and Figure 2-2, according to the reliability analysis, the reliability of series-connected after parallel-connected is better than parallelconnected after series-connected and the reliability is higher than the monomer battery. Selfregulation ability in the connection mode as shown in Figure 2-1 is superior to the mode as shown in Figure 2-2 when the monomer battery fails. So the system with series-connected after parallel-connected is better than others, and it commonly is used in practical application.

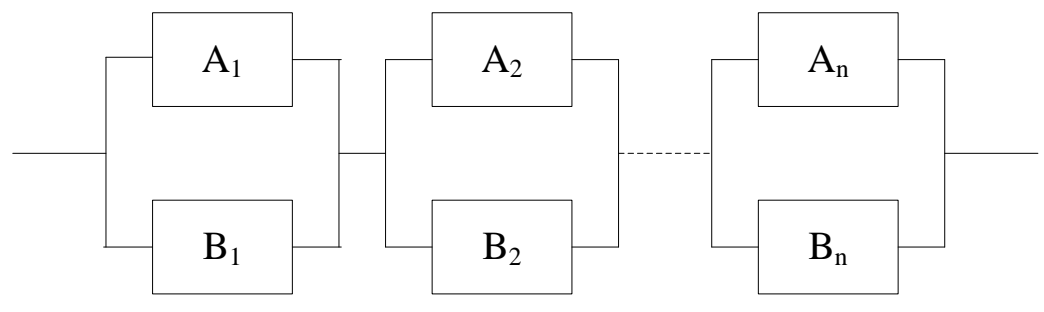

Figure 2-1. First parallel -series connection

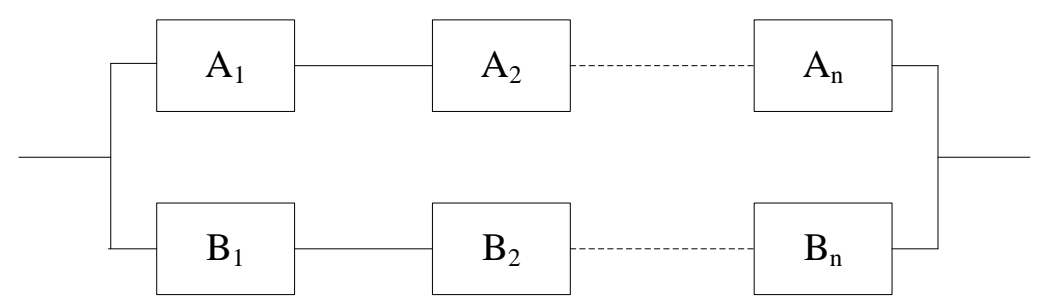

Figure 2-2. First series-parallel connection

In Figure 2-1, parallel branch is a basic component unit of the connection scheme and the structure is shown in Figure 2-3, their relationships are:

$$
\begin{aligned}
& I_{1}=\left(E_{1}-U\right) / R_{1} \\
& I_{2}=\left(E_{2}-U\right) / R_{2} \\
& I_{3}=\left(E_{3}-U\right) / R_{3}
\end{aligned}
$$




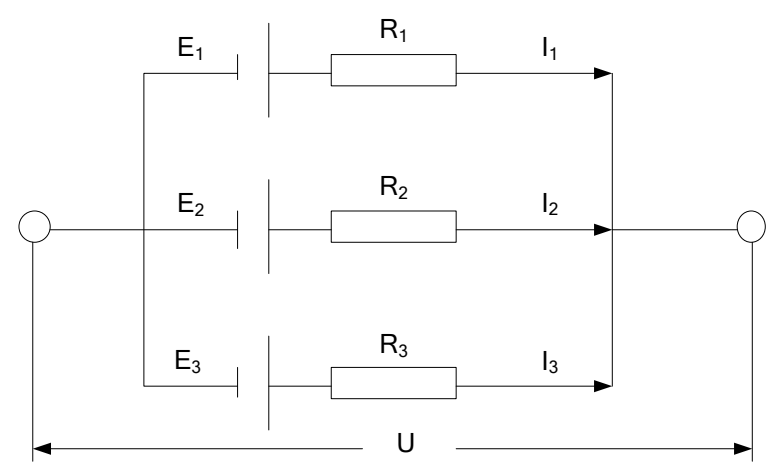

Figure 2-3. Parallel circuit

Conclusion from the above analysis, the changes of $U$ are consistent in the parallel connection branch. Assuming that $\mathrm{E}_{1}=\mathrm{E}_{2}=\mathrm{E}_{3}, \mathrm{I}_{1} \mathrm{R}_{1}=\mathrm{I}_{2} \mathrm{R}_{2}=\mathrm{I}_{3} \mathrm{R}_{3}$, so the smaller the resistance of the monomer battery is, the greater the current is, and the greater the resistance is, the smaller the current is. As $\mathrm{W}=\mathrm{I}_{2} \mathrm{R}$ shown, the losses of energy is different, the energy emitted by battery is different, and the battery discharge depth is different. In the process of discharge, the parallel monomer battery charging current is different, because the internal resistance of the battery is not the same, which leads to the different charging rate, ultimately affects the charging process.

The smaller the difference of battery internal resistance is, the consistency is better, namely, $R_{1}: R_{2}: R_{3}$ are closed to 1 . So the battery internal resistance difference can be used as a consistency evaluation norm of the battery.

\section{Freedom CAR Battery Model}

Due to it is difficult to measure the internal resistance of the battery, so establishing the FreedomCAR equivalent circuit model which is based on the working principle of the battery. It provides a short path to evaluate the consistency of the battery internal resistance [9].

To use the simulative circuit elements such as resistor, capacitor, and constant voltage power to constitute the circuit model, to simulate the dynamic characteristics of the battery. FreedomCAR proposed circuit model for describing the battery is shown in Figure 2-4, the model consists of five parts, each section describes different performances of the battery, and five parts constitute a complete battery.

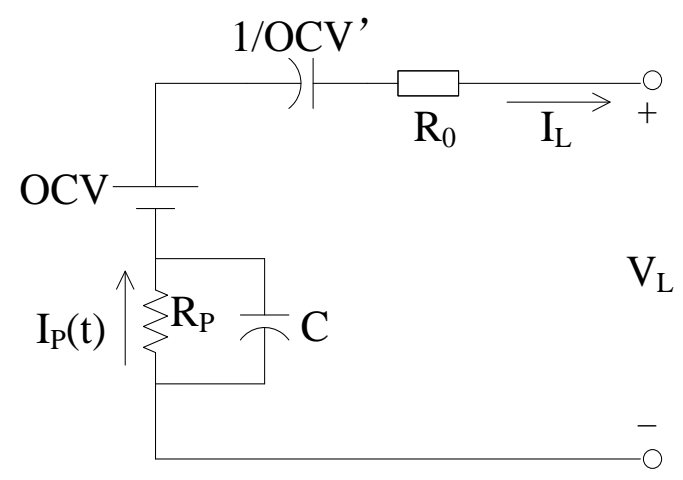

Figure 2-4. Freedom CAR battery model 
In the model, OCV is the open circuit voltage of the battery; $\mathrm{R}_{0}$ is the ohm internal resistance of the battery; $R_{P}$ is the polarization resistance of the battery; The sum of the ohm resistance $R_{0}$ and the polarization resistance $R_{P}$ is the battery internal resistance $R ; C$ is the impedance around the polarization resistance $\mathrm{R}_{\mathrm{P}} ; \mathrm{V}_{\mathrm{L}}$ is the battery voltage on both ends when the battery works; $I_{L}$ is the battery load current; $I_{P}$ is the current through the polarization resistance.

Through the analysis, some of the parameters can be measured, but some can not be measured, they need mathematical calculations. According to the above circuit model and Kirchhoff's voltage law, we can write equations:

$$
\begin{gathered}
V_{L}=O C V-O C V^{\prime}\left\lfloor\int I_{L} d t\right]-R_{0}\left[I_{L}\right]-R_{P}\left[I_{P}\right] \\
\frac{d I_{P}}{d t}=\frac{I_{L}-I_{P}}{\tau}
\end{gathered}
$$

Resolving equation (1) through discretization, we can get the following equations:

$$
\begin{gathered}
V_{L, i(e s t)}=O C V+O C V^{\prime} \cdot\left(\sum I_{L} \Delta t\right)_{i}-I_{L, i} \cdot R_{0}-I_{P, i} \cdot R_{P} \\
{[Y]=b+m_{1}\left[X_{1}\right]+m_{2}\left[X_{2}\right]+m_{3}\left[X_{3}\right]}
\end{gathered}
$$

In the equation (1), $V_{L}, \quad I_{L}$ and $t$ can be measured; $I_{P}$ can be obtained through equation (4); $\mathrm{OCV}, \mathrm{OCV}, \mathrm{R}_{0}$ and $\mathrm{R}_{\mathrm{P}}$ can be calculated through linear regression algorithm.

From initial conditions $I_{P}(t=0)=0$, if given each sample I, solving differential equation (2) by discretization:

$$
\left.I_{P, i}=\left\{1-\left[\frac{1-e^{\frac{-\Delta t}{\tau}}}{\frac{-\Delta t}{\tau}}\right]\right\} \cdot I_{L, i}+\left\{\frac{1-e^{\frac{-\Delta t}{\tau}}}{-\Delta t}\right]-e^{\frac{-\Delta t}{\tau}}\right\} \cdot I_{L, i-1}-\left\{e^{\frac{-\Delta t}{\tau}}\right\} \cdot I_{P, i-1}
$$

Through the figure (1) of the battery circuit model, we know $\mathrm{V}_{\mathrm{L}}$ is the battery voltage on both ends, it can be measured, and it also can be estimated through equation (3). By comparing the $\mathrm{V}_{\mathrm{L}}$ which is measured and the terminal voltage $V_{L, i(e s t)}$ which is estimated by calculation, estimation error is represented by $\Delta V_{i}$.

$$
\Delta V_{i}=V_{L, i(e s t)}-V_{L, i}
$$

Through adjusting the polarization time parameter $\tau$, we can improve the prediction accuracy of $V_{L, i(e s t)}$, reducing the estimation error $\Delta V_{i}$. The error between the measured voltage $V_{L, i}$ and $V_{L, i(e s t)}$ can be represented by covariance $r^{2}$, through adjusting $\tau$ constantly, we can make $r^{2}>0.995$. In FreedomCAR battery model, OCV, OCV', $\mathrm{R}_{0}$ and $\mathrm{R}_{\mathrm{P}}$ can be calculated through Matlab software by the algorithm of linear regression, the specific steps are as follows: 
Firstly, to set the covariance $r^{2}$ that is represented by the error between measured values and estimated values and the polarization time parameter $\tau$ in an expected beginning value. Then putting the data which are measured by battery test system into Matlab program, the measured data include: time vector $T$, load current $\mathrm{I}_{\mathrm{L}}$, terminal voltage vector $\mathrm{V}_{\mathrm{L}}$ which is measured. Polarization current $I_{P}$ that is calculated by Runge kutta method. Then to use $I_{P}$ that is calculated and the data which are measured by battery test system, to calculate OCV, OCV', $R_{P}$ and $R_{0}$ through Matlab program by the algorithm of linear regression. Then we can get terminal voltage vector $V_{L, i(e s t)}$ through input data and calculated data, we will get terminal voltage error vector $\Delta V$ through subtracting the measured $\mathrm{V}_{\mathrm{L}}$.

In Matlab program, $I_{p}, I_{L}, V_{L,(e s t)}, V_{L}$ and $\Delta V$ can be shown through Matlab figure. In the program loop, adjusting the polarization parameters constantly, the terminal voltage error covariance parameters tend to be the maximum, and then the estimated value of terminal voltage is more close to the measured value [10].

\section{Identification Experiment and Analysis of Model Data}

In order to identify the parameters of FreedomCAR equivalent circuit model, we need monomer battery test, collecting the terminal voltage $\mathrm{V}_{\mathrm{L}}$ of the battery and load current $\mathrm{I}_{\mathrm{L}}$ in the whole charge and discharge cycles. Editing Excel spreadsheet of the measured data, we may obtain characteristic parameters of the battery model through the LINEST function [11]. According to the HPPC test in FreedomCAR Battery Test Manual proceeding in the interval for $10 \%$ of the SOC according to charging current graphics in Figure 2-5, using 20C pulse discharges respectively, SOC rang from $100 \%$ to $10 \%$, the time interval between adjacent pulses is $10 \mathrm{sec}$. Performing experiment and recording, the time of data collection is $0.133 \mathrm{~s}$, Figure 2-6 is corresponding voltage curve when pulse discharges.

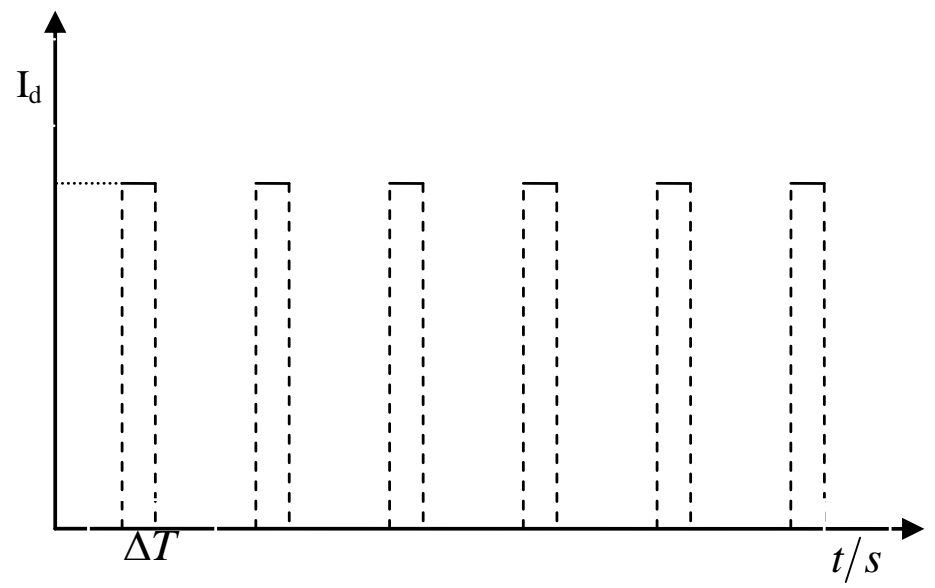

Figure 2-5. FreedomCAR battery model experimental current of discharge 


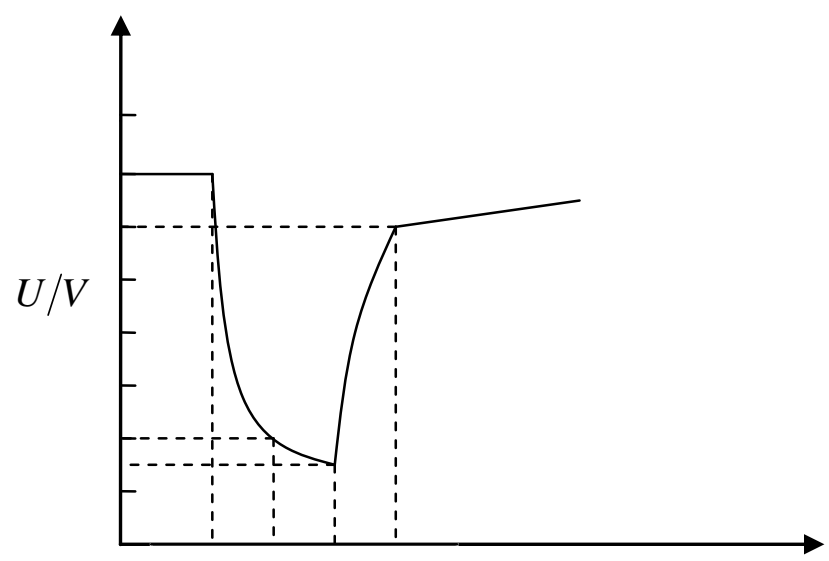

$\begin{array}{llll}\mathrm{T}_{1} & \mathrm{~T}_{2} & \mathrm{~T}_{3} & \mathrm{~T}_{4}\end{array}$

Figure 2-6. FreedomCAR model battery corresponding voltage curve when pulse discharges

Linear battery voltage $\mathrm{V}_{\mathrm{L}}$ at both ends can be measured, we can also get the estimated value $V_{L, i(e s t)}$ according to the numerical from the previous discrete point through equation (1), and we may obtain error $\Delta V_{i}$ by comparing the battery measurements and estimates. We can obtain $\Delta V_{i}$ is within the scope of the permit by analyzing the experimental results, it illustrates that it is feasible to use LINEST's linear regression algorithm in FreedomCAR model [12].

The internal resistance parameter values and measured values of the battery in FreedomCAR model through linear regression algorithm are shown in Figure 2-7.

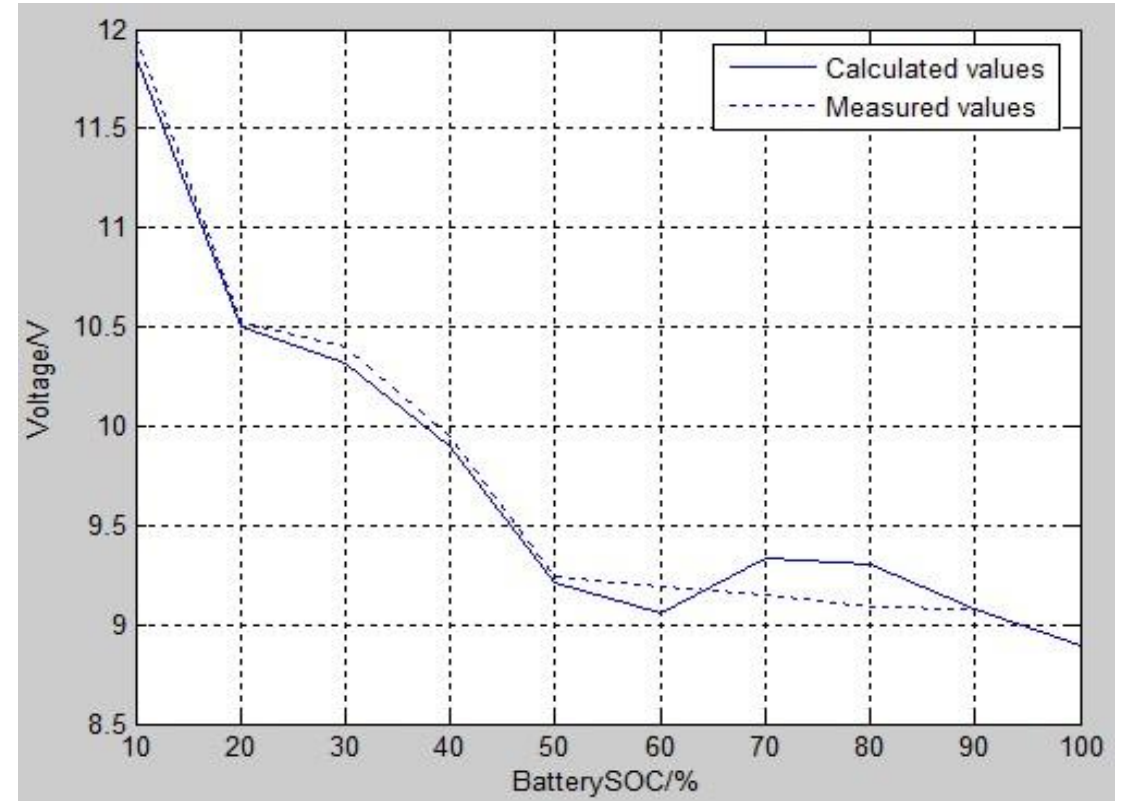

Figure 2-7. Calculated values and measured values of the battery internal resistance 
From Figure 2-7, we know that the error $\Delta V_{i}$ between calculated values and measured values of the battery is the maximum when the battery SOC is $80 \%$, and $\Delta V_{i}=2.1 \%$, the average error is:

$$
\lim _{n \rightarrow \infty}\left(\sum_{i=1}^{n} \Delta V_{i}\right) / n=0.2 \%
$$

The battery parameters which are obtained through observing and analyzing have explicit physical meanings, and the parameters through the model identification and the measured data through the internal resistance tester are anastigmatic under different SOC. It proves that FreedomCAR battery model can accurately reflect the dynamic features when the battery works in dynamic condition, it can be applied in the monomer battery characteristics test.

\section{Conclusions}

The parameters in FreedomCAR model have explicit physical meanings, the parameter of model internal resistance and battery internal resistance are anastigmatic through experimental verification, the model is suitable for modeling and simulating to lithium ion battery, the precision of simulation is higher. The internal resistance that gets from the model and algorithm provides a shortcut for the evaluation of the monomer battery's consistency.

\section{References}

[1] V. H. Johnson, "Battery Performance Models in ADVISOR”, Journal of Power Sources, vol. 110, no. 321, (2002).

[2] B. Zhang, L. Guo, H. Li, Q. Chen and Z. Cui, "PNGV Model Analysis of Electric Cars with Iron Phosphate Lithium-ion Battery”, Power Supply Technology, (2009), pp. 417-421.

[3] H. Culcu and N. Omar, "FreedomCAR Model Internal Resistance of Cells of Lithium Battery", World Electric Vehicle Joumal, vol. 3, (2005).

[4] C. Lin, B. Qiu and Q. Chen, "Research on Nonlinear Equivalent Circuit Model of the Electric Car Battery", Automotive Engineering, (2006), pp. 38-47.

[5] P. J. Chin and R. Ebernhart, "Battery Pack State of Charge Estimator Design Using Computational Intelligence Approaches", Long Beach, IEEE Transactions on Industrial Electronics, (2000), pp. 1343-1349.

[6] F. Wang, B. Fan, S. Liu, G. Qian, Q. Huang and S. Han, "Attenuation of Vehicle Power Battery Cycle Life Test and Fitting", Journal of Automotive Safety and Energy Saving, (2012), pp. 71-76.

[7] Y. Jia, D. Xie, Y. Gu, X. Ai, Z. Jin and J. Gu, "Classification and Characteristics of the Electric Car Battery Equivalent Circuit Model”, Power and Energy, (2011), pp. 516-521.

[8] S. Abu-Sharkh and D. Doerffel, "Rapid Test and Non-linear Model Characterization of Solid-state Lithium-ion Batteries", Journal of Power Sources, (2004).

[9] Q. Chen and C. Lin, "Research and Review of the Electric Car Battery Performance Model, Machine Technology, (2005), pp. 1-5.

[10] B Schweighofer, K. M. Raab and G Brasseur, "Modeling of High Power Automotive Batteries by the Use of an Automated Test System", IEEE Trans Instrumentation and Measurement, (2003).

[11] J. Chen, C. Zhou and W. Cheng, "Area Error Analysis of the Planar Elements in GIS Vector", Journal of Surveying and Mapping, (2007), pp. 344-350.

[12]X. Ding, L. Zhou and J. Zhou, "The Space of the Robot Posture Error Analysis Method", Journal of Beijing University of Aeronautics and Astronautics, (2009), pp. 241-245. 
International Journal of Control and Automation Vol.7, No.3 (2014) 